\title{
SCHOOL CHOICE UNDER COMPLETE INFORMATION: AN EXPERIMENTAL STUDY
}

\author{
Yan Chen \\ University of Michigan, USA, and Tsinghua University, China \\ yanchen@umich. edu \\ Yingzhi Liang \\ University of Michigan, USA \\ yingzhi@umich.edu \\ Tayfun Sönmez \\ Boston College, USA \\ sonmeztabc.edu
}

\begin{abstract}
We present an experimental study of three school choice mechanisms under complete information, using the designed environment in Chen \& Sönmez (2006). We find that the top trading cycles (TTC) mechanism outperforms both the Gale-Shapley deferred acceptance (DA) and the Boston immediate acceptance (BOS) mechanism in terms of truth-telling and efficiency, whereas DA is more stable than either TTC or BOS. Compared to the incomplete information setting in Chen \& Sönmez (2006), the performance of both TTC and BOS improves with more information, whereas that of DA does not.
\end{abstract}

Keywords: School choice, experiment, mechanism design.

JEL Classification Numbers: C78, C92, D82.

We thank Alexandra (Sasha) Killewald and Kan Takeuchi for excellent research assistance. Financial support from the National Science Foundation through grant no. SES-0962492 to Chen is gratefully acknowledged. This research was approved by the University of Michigan IRB.

Copyright (C) Yan Chen, Yingzhi Liang, Tayfun Sönmez / 1(1), 2016, 45-82. 


\section{INTRODUCTION}

C chool choice mechanisms affect the educational experiences and outcomes $\boldsymbol{N}$ of many students around the world. The past two decades have witnessed major reforms in this domain. In designing practical markets, institutions have relied on economic theory, computation, and controlled laboratory experiments (Roth, 2002). For example, shortly after the publication of Abdulkadiroğlu \& Sönmez (2003), New York City high schools replaced their previous mechanism with a variant of the student-proposing deferred-acceptance (DA) mechanism (Gale \& Shapley, 1962; Abdulkadiroğlu, Pathak, \& Roth, 2005). In the school choice reforms in Boston, matching theorists directly influenced the adoption of the DA mechanism (Abdulkadiroğlu, Pathak, Roth, \& Sönmez, 2005). In this case, experimental data helped persuade the Boston public school authorities to switch from the Boston immediate acceptance mechanism (BOS) to DA (Chen \& Sönmez, 2006). In parallel with these reforms, policy makers in Chicago and in New England independently abandoned the Boston mechanism and adopted versions of the DA (Pathak \& Sönmez, 2013). Laboratory experiments provide the first data for institutional redesigns when field data is not yet available. Even when field data is available, lab experiments compare the performance of different mechanisms at a level of detail that cannot be obtained from field data.

In an incomplete information setting, Chen \& Sönmez (2006) present the first experimental study of three well-known school choice mechanisms, BOS, DA and the top trading cycles (TTC). They find that DA outperforms TTC in truthful preference revelation, despite the strategy-proofness of both mechanisms. Furthermore, they show that TTC does not outperform DA in efficiency, although theoretically it is efficient whereas DA is not. Among the three mechanisms, BOS performs the worst in terms of truthful preference revelation and efficiency. While a stability comparison is not presented in Chen \& Sönmez (2006), using the same experimental setting, Calsamiglia et al. (2010) find that DA is more stable than TTC, which in turn is weakly more stable than BOS.

In this paper, we ask two questions. First, how do the three school choice mechanisms perform in a complete information setting? Second, how does information provision affect the performance of each mechanism?

To answer these questions, we run an experiment under the complete information setting, using the same set of parameters as in the designed environment 
in Chen \& Sönmez (2006), which enables us to compare our results with their earlier study. Our results show that, in the complete information setting, TTC outperforms DA, which in turn outperforms BOS in truth-telling. Consistent with theory, TTC outperforms both DA and BOS in efficiency, whereas DA and BOS generate similar efficiency levels. In terms of stability, DA outperforms TTC and BOS by a large margin, whereas BOS and TTC achieve the same level of stability. In summary, information affects the performance of the three mechanisms in different ways. More information improves the performance of both TTC and BOS, but does not change either efficiency or stability under DA.

Our findings have clear policy implications. A market designer who values efficiency over stability should adopt TTC and encourage information provision. In comparison, a market designer who values stability over efficiency should adopt DA.

The rest of the paper is organized as follows. Section 2 reviews the experimental school choice literature. Section 3 introduces the school choice problem and summarizes the theoretical properties of the three mechanisms. Section 4 presents the experimental design. Section 5 summarizes the main results. Section 6 concludes the paper. Instructions for experiment are given in the Supplement before references.

\section{LITERATURE REVIEW}

With the development of matching theory in the school choice domain (Abdulkadiroğlu \& Sönmez, 2003), a growing number of laboratory experiments have tested the performance of school choice mechanisms as well as participant behavior under different incentives.

In the first experimental study of school choice mechanisms, Chen \& Sönmez (2006) deploy a setting with 36 students and 7 schools per match. Schools differ in their capacity, location, quality and strength. Student preferences are induced in two different environments. One is the designed environment, where student preferences are generated based on their distance to the school and their interests. To provide a robustness check, a random environment is used where student preferences are randomly generated. They use an incomplete information setting, where students only know their own preference, their district schools, and school capacities. They find that DA outperforms TTC in truthful preference revelation, whereas TTC does not 
outperform DA in efficiency. Of the three mechanisms, BOS performs the worst in truthful preference revelation and efficiency. We use the same set of parameters as in their designed environment but with complete information.

Closely related to our study, Pais \& Pintér (2008) investigate the impact of different information conditions on the performance of the same three school choice mechanisms, but with a relatively small group size (five students and three schools per match). They find that under complete information, TTC outperforms both BOS and DA in terms of truthful preference revelation and efficiency, while the three mechanisms perform similarly in stability. Overall, they find that TTC is less sensitive to the amount of information provided to the participants.

Subsequent experimental studies have examined the impact of a limit on the number of schools in the rank order list (Calsamiglia et al., 2010), participant risk attitude and preference intensities (Klijn et al., 2013), peer information sharing in networks (Ding \& Schotter, 2016) and intergenerational advice (Ding \& Schotter, 2015) on participant behavior.

Two other studies investigate the effects of information conditions on individual behavior and mechanism performance. In an interim Bayesian setting, Featherstone \& Niederle (2013) observe that BOS achieves higher efficiency than DA when school priorities involve ties which are broken randomly. More recently, Chen \& He (2016) study endogenous information acquisition under BOS and DA in the school choice setting. They find that information provision of students' own and other's preferences improves efficiency.

\section{THREE SCHOOL CHOICE MECHANISMS}

In this section, we introduce the school choice problem and the three mechanisms. In a school choice problem, there are a number of students, and a number of schools. Each student has strict preference over all schools, whereas each school has a maximum capacity and a strict priority ordering of all students. School priorities are imposed by the school district based on state and local laws (Abdulkadiroğlu \& Sönmez, 2003).

The outcome of a school choice problem is referred to as a matching, which is an assignment of school seats to students such that each student is assigned one seat and no school assigns more seats than its capacity. A matching is Pareto efficient if there is no matching which assigns each student a weakly better school and at least one student a strictly better school. A blocking pair 
consists of a student-school pair $(i, s)$ such that: (1) student $i$ prefers school $s$ to her assignment under $\mu$ and (2) student $i$ has higher priority at school $s$ than some other student who is assigned a seat at school $s$ under $\mu$. A matching $\mu$ eliminates justified envy if there is no blocking pair.

Finally, a student assignment mechanism is a systematic procedure that selects a matching for each school choice problem. A mechanism is Pareto efficient if it always selects a Pareto efficient matching; it is stable if it always selects a matching which eliminates justified envy; it is strategy-proof if no student can possibly benefit by unilaterally misrepresenting her preferences.

In the school choice literature, three mechanisms have been studied extensively: the Boston immediate acceptance mechanism, the Gale-Shapley deferred acceptance mechanism and the top trading cycle mechanism. We now briefly describe each mechanism and summarize their theoretical properties.

The Boston immediate acceptance mechanism (BOS) asks students to submit rank order lists (ROL) of schools. Together with the pre-announced capacity of each school, BOS uses pre-defined rules to determine the school priority ranking over students and consists of the following rounds:

Round 1. Each school considers all students who rank it first and assigns its seats in order of their priority at that school until either there is no seat left at that school or no such student left.

Generally, in:

Round $(k>1)$. The $k$ th choice of the students who have not yet been assigned is considered. Each school that still has available seats assigns the remaining seats to students who rank it as their $k$ th choice in order of their priority at that school until either there is no seat left at that school or no such student left.

The process terminates after any round $k$ when either every student is assigned a seat at some school, or the only students who remain unassigned have listed no more than $k$ choices.

Ergin \& Sönmez (2006) characterize the Nash equilibria of the BOS mechanism, showing that its equilibria are either equal to or Pareto inferior to the dominant strategy outcome of DA. The BOS mechanism was adopted for student assignment to public schools in Boston from 1999 to 2005, when it was replaced by DA (Abdulkadiroğlu \& Sönmez, 2003; Abdulkadiroğlu et al., 2006). It has been widely used in other regions as well, including Cambridge, Denver, Minneapolis, Seattle, St. Petersburg-Tampa (Chen \& Sönmez, 2006) and Beijing (He, 2014). Despite its popularity, BOS is neither strategy-proof 
nor stable. BOS also tends to favor strategically sophisticated students (Pathak \& Sönmez, 2008). Because of these shortcomings, Abdulkadiroğlu \& Sönmez (2003) propose two strategy-proof alternatives, DA and TTC.

The Gale-Shapley deferred acceptance mechanism (DA) is proposed by Gale \& Shapley (1962) in the college admission context. It is then analyzed in the school choice context by Abdulkadiroğlu \& Sönmez (2003). Specifically, the mechanism collects school capacities and student ROLs for schools. With strict rankings of schools over students that are determined by pre-specified rules, it proceeds as follows:

Round 1. Every student applies to her first choice. Each school rejects the least ranked students in excess of its capacity and temporarily holds the others.

Generally, in:

Round $(k>1)$. Every student who is rejected in Round $(k-1)$ applies to the $k^{\text {th }}$ choice on her list. Each school pools together new applicants and those on hold from Round $(k-1)$. It then rejects the least ranked students in excess of its capacity. Those who are not rejected are temporarily held.

The process terminates after any Round $k$ when no rejections are issued. Each school is then matched with those students whom it is currently holding.

DA is strategy-proof and stable. Though it is not efficient, it Pareto dominates any other mechanism that eliminates justified envy (Dubins \& Freedman, 1981; Roth, 1982). As mentioned in the introduction, various versions of the DA has been adopted to replace BOS in Boston and New York City for school choice, throughout England for public school assignment (Pathak \& Sönmez, 2013), and by many provinces in Chinese college admissions (Chen \& Kesten, 2017).

While DA preserves stability at the cost of Pareto efficiency, the top trading cycles mechanism (TTC) preserves efficiency at the cost of stability (Abdulkadiroğlu \& Sönmez, 2003). In what follows, we adopt the description of the TTC from Chen \& Sönmez (2006). In our experimental setting, each student has a high priority at her district school and low priority at other schools. At each school, the priority among high priority students, as well as the priority among low priority students, is determined with a single tie-breaking lottery. In this case, the TTC mechanism works as follows:

1. For each school, a priority ordering of students is determined.

2. Each student submits a preference ranking of the schools. 
3. Based on the submitted preferences and priorities, the student assignment is determined as follows:

(a) Each participant is tentatively assigned a seat at her district school.

(b) All participants are lined up in an initial queue based on the tiebreaking lottery.

(c) An application to the highest-ranked school is made on behalf of the participant at the top of the queue.

- If the application is made to her district school, then her tentative assignment is finalized. The participant and her assignment are removed from the system. The process continues with the next participant in line.

- If the application is made to another school, say school $s$, then the first participant in the queue who tentatively holds a seat at school $s$ is moved to the top of the queue directly in front of the requester.

(d) Whenever the queue is modified, the process continues similarly: an application to the highest ranked school with still available seats is made on behalf of the participant at the top of the queue.

- If the application is made to her district school, then her tentative assignment is finalized. The participant and her assignment are removed from the system. The process continues with the next participant in line.

- If the application is made to another school, say school $s$, then the first participant in the queue who tentatively holds a seat at school $s$ is moved to the top of the queue directly in front of the requester.

(e) A mutually-beneficial exchange is obtained when a cycle of applications is made in sequence (e.g., I apply to John's district school, John applies to your district school and you apply to my district school). In this case, the Pareto-improving exchange is carried out and the participants, as well as their assignments, are removed from the system.

(f) The process continues until all participants are assigned a school seat. 
TTC has been adopted by the city of New Orleans in its school choice program implemented since 2012 (Vanacore, 2012). In theory, the TTC mechanism has an efficiency advantage over both BOS and DA. The DA mechanism, on the other hand, is stable, whereas neither BOS or TTC is. In terms of preference manipulation, we expect a high (low) proportion of truth-telling under both the DA and TTC (BOS), based on the strategy-proofness of DA and TTC. We will summarize the theoretical properties of each mechanism as hypotheses in Section 5.

\section{EXPERIMENTAL DESIGN}

We use the same set of parameters as the designed environment in Chen \& Sönmez (2006). There are 36 students and 7 schools per match. Schools have different capacities. Schools A and B are small and high quality schools, with 3 seats each, whereas school $\mathrm{C}$ to $\mathrm{G}$ are lower quality schools with 6 seats each. Each student has a district school where she has the highest priority.

The induced student preferences over schools is generated by a utility function, which depends on the school quality, proximity, and a random factor. The utility function of each student has three components, $u^{i}(S)=u_{p}^{i}(S)+$ $u_{q}^{i}(S)+u_{r}^{i}(S)$. Here $u_{p}^{i}(S)$ represents the proximity utility for student $i$ at school $S$. This utility is 10 if student $i$ lives within the walk zone of school $S$ and zero otherwise. The second component, $u_{q}^{i}(S)$, represents the quality utility for student $i$ at school $S$. For odd-labelled students (i.e., for students who are gifted in sciences), $u_{q}^{i}(A)=20, u_{q}^{i}(B)=40$, and $u_{q}^{i}(S)=10$ for $S \in\{C, D, E, F, G\}$. For even-labelled students (i.e., for students who are gifted in arts), $u_{q}^{i}(A)=40, u_{q}^{i}(B)=20$, and $u_{q}^{i}(S)=10$ for $S \in\{C, D, E, F, G\}$. Lastly, the third component, $u_{r}^{i}(S)$, represents a random utility (uniform in the range 0-40) which captures diversity in tastes.

Table 1 presents the monetary payoff of each student for being matched with each school. Boldfaced numbers indicate that the student lives within the school district of that school. For example, participant with ID \#1 lives in the school district of school A. She will get $\$ 13$ dollars if she gets admitted to school A, \$16 dollars if she gets admitted to school B, and so on.

Our design differs from Chen \& Sönmez (2006) in the amount of information provided to our participants. While a student knows only her own row of the payoff table, her own district school and school capacities in Chen \& Sönmez (2006), we implement a complete information setting, where students 
Table 1: Payoff Table

\begin{tabular}{|c|c|c|c|c|c|c|c|}
\hline \multirow[b]{2}{*}{ Student ID } & \multicolumn{7}{|c|}{ Schools } \\
\hline & $\mathrm{A}$ & B & $\mathrm{C}$ & $\mathrm{D}$ & $\mathrm{E}$ & $\mathrm{F}$ & $\mathrm{G}$ \\
\hline 1 & 13 & 16 & 9 & 2 & 5 & 11 & 7 \\
\hline 2 & 16 & 13 & 11 & 7 & 2 & 5 & 9 \\
\hline 3 & 11 & 13 & 7 & 16 & 2 & 9 & 5 \\
\hline 4 & 16 & 13 & 11 & 5 & 2 & 7 & 9 \\
\hline 5 & 11 & 16 & 2 & 5 & 13 & 7 & 9 \\
\hline 6 & 16 & 13 & 7 & 9 & 11 & 2 & 5 \\
\hline 7 & 13 & 16 & 9 & 5 & 11 & 7 & 2 \\
\hline 8 & 16 & 9 & 11 & 2 & 13 & 7 & 5 \\
\hline 9 & 16 & 13 & 2 & 5 & 9 & 7 & 11 \\
\hline 10 & 16 & 7 & 9 & 5 & 2 & 11 & 13 \\
\hline 11 & 7 & 16 & 11 & 9 & 5 & 2 & 13 \\
\hline 12 & 13 & 16 & 9 & 11 & 2 & 7 & 5 \\
\hline 13 & 9 & 16 & 2 & 13 & 11 & 5 & 7 \\
\hline 14 & 16 & 5 & 2 & 9 & 7 & 13 & 11 \\
\hline 15 & 13 & 16 & 9 & 11 & 2 & 7 & 5 \\
\hline 16 & 16 & 13 & 11 & 5 & 9 & 7 & 2 \\
\hline 17 & 13 & 16 & 5 & 7 & 2 & 9 & 11 \\
\hline 18 & 16 & 13 & 5 & 9 & 7 & 11 & 2 \\
\hline 19 & 11 & 16 & 7 & 5 & 13 & 9 & 2 \\
\hline 20 & 16 & 13 & 7 & 9 & 5 & 2 & 11 \\
\hline 21 & 13 & 16 & 2 & 7 & 9 & 11 & 5 \\
\hline 22 & 16 & 11 & 7 & 2 & 9 & 5 & 13 \\
\hline 23 & 16 & 13 & 7 & 2 & 5 & 11 & 9 \\
\hline 24 & 16 & 13 & 11 & 5 & 9 & 2 & 7 \\
\hline 25 & 13 & 16 & 2 & 5 & 11 & 9 & 7 \\
\hline 26 & 16 & 13 & 5 & 9 & 7 & 2 & 11 \\
\hline 27 & 7 & 11 & 5 & 2 & 13 & 9 & 16 \\
\hline 28 & 16 & 13 & 7 & 2 & 11 & 5 & 9 \\
\hline 29 & 7 & 11 & 16 & 13 & 2 & 9 & 5 \\
\hline 30 & 16 & 9 & 7 & 2 & 5 & 11 & 13 \\
\hline 31 & 11 & 16 & 7 & 2 & 5 & 9 & 13 \\
\hline 32 & 13 & 9 & 16 & 2 & 5 & 7 & 11 \\
\hline 33 & 13 & 16 & 11 & 9 & 7 & 5 & 2 \\
\hline 34 & 16 & 11 & 2 & 7 & 5 & 13 & 9 \\
\hline 35 & 7 & 16 & 2 & 5 & 11 & 13 & 9 \\
\hline 36 & 16 & 13 & 5 & 7 & 9 & 2 & 11 \\
\hline
\end{tabular}


know every student's preference, i.e., the entire payoff table, school priority and capacity for every school, and every student's position in the randomly generated tie-breaker before making a decision.

In the experiment, each subject is randomly assigned an ID number and is seated in a chair in a classroom. All sessions are conducted by hand. At the beginning of the first session, participants are asked to volunteer to generate the random tie-breaker. One volunteer is asked to come to the front of the classroom and draw ping pong balls (labelled 1-36), one at a time, from an urn. The volunteer announces the number on each ball, which is recorded on a transparency in public by the experimenter. This tie-breaker is then used in all subsequent sessions. The random tie-breaker used in our experiment is as follows:

$[6,19,15,10,33,24,1,28,30,32,4,25,21,14,23,16,5,35,29,8,22,2,13,12$, $18,9,20,17,7,34,11,31,3,36,27,26]$.

This means that participant with ID \#6 has the highest priority, participant with ID \#19 has the second highest priority, and so on.

At the beginning of each session, after subjects are seated in a classroom, the experimenter reads the instructions aloud. Subjects are then given fifteen minutes to read the instructions at their own pace and to make their decisions. At the end of fifteen minutes, the experimenter collects the decision sheets. The session ends after the decision sheets are collected. The experimenter then puts the subject decisions and the lottery into a computer program to generate the allocations, announces the allocations by email and pays the subjects after the email announcement.

Table 2: Features of experimental sessions

\begin{tabular}{lccc}
\hline \hline Mechanism & Subjects per session & \# of sessions & Total \# of subjects \\
\hline BOS $_{c}$ & 36 & 2 & 72 \\
DA $_{c}$ & 36 & 2 & 72 \\
TTC $_{c}$ & 36 & 2 & 72 \\
\hline
\end{tabular}

Table 2 summarizes features of experimental sessions. We conduct two independent sessions for each mechanism in spring 2004 at the University of Michigan. Subjects are undergraduate students from the University of 
Michigan. Each sessions has 36 subjects. This gives us 72 subjects for each mechanism and 216 subjects in total. Each session consists of one round only. The session lasts between 45-60 minutes, with the first 20-25 minutes being used for instructions. The average payment (including a $\$ 3$ participation fee) is $\$ 14.73$. No subject participates in more than one session. In addition, when we compare subject behavior under complete information to that under incomplete information, we re-use the data from the 216 subjects in the designed environment in Chen \& Sönmez (2006). Thus, we use data from a total of 432 subjects in our analysis. Experimental instructions are included in the Appendix. Data are available from the authors upon request.

\section{RESULTS}

Several questions are important in evaluating the mechanisms. The first is whether individuals report their preferences truthfully. The second is the rankings of mechanisms in terms of efficiency or stability. The third is whether the experimental results are robust to changes in the information condition.

In presenting the results, we introduce some shorthand notations. Let $x>y$ denote that a measure under mechanism $x$ is greater than the corresponding measure under mechanism $y$ at the $5 \%$ significance level. Let $x \geq y$ denote that a measure under mechanism $x$ is greater than the corresponding measure under mechanism $y$ at the $10 \%$ significance level. Let $x \sim y$ denote that a measure under mechanism $x$ is not significantly different from the corresponding measure under mechanism $y$ at the $10 \%$ significance level.

We first examine whether individuals reveal their preferences truthfully, and if not, how they manipulate their preferences under each of the three mechanisms. We then report how information affects truth-telling. Based on their theoretical properties, we formulate the following hypothesis:

Hypothesis 1 (Truth-telling). (a) Under DA or TTC, participants will be more likely to reveal their preferences truthfully than under BOS. (b) Participants will be equally likely to reveal their preferences truthfully under either DA or TTC. (c) The likelihood of truth-telling under either DA or TTC remains the same when more information is provided.

Note that in Hypothesis 1(c), we are silent about whether the proportion of truth-telling under BOS might change when more information is provided. This is due to the fact that the extent to which information might influence 
school choice strategies depends on the environment (Ergin \& Sönmez, 2006; Abdulkadiroğlu et al., 2011). Following the experimental school choice literature (Chen \& Sönmez, 2006; Pais \& Pintér, 2008; Calsamiglia et al., 2010; Pais et al., 2011), we separate participant strategies into three categories: truthtelling, district school bias (DSB), and other strategies. Formally, district school bias is defined as putting one's district school into a higher position than that in one's true preference order. Under TTC and DA, the ranking of schools below one's district school does not matter. Therefore, under these two mechanisms, we code a ROL as truthful as long as the list from one's first choice to one's district school is truthful. In comparison, under BOS, we use the complete ROL to measure truth-telling.

Table 3: Proportion of truth-telling and misrepresentations

\begin{tabular}{|c|c|c|c|c|c|c|c|}
\hline \multicolumn{4}{|c|}{ Complete Information } & \multicolumn{4}{|c|}{ Incomplete Information (CS 2006) } \\
\hline Mechanism & Truth-telling & DSB & Other & Mechanism & Truth-telling & DSB & Other \\
\hline$B O S_{c}$ & 0.194 & 0.611 & 0.194 & $B O S_{i}$ & 0.111 & 0.750 & 0.139 \\
\hline$D A_{c}$ & 0.542 & 0.153 & 0.306 & $D A_{i}$ & 0.722 & 0.083 & 0.194 \\
\hline$T T C_{c}$ & 0.708 & 0.083 & 0.208 & $T T C_{i}$ & 0.500 & 0.292 & 0.208 \\
\hline
\end{tabular}

Table 3 reports the proportion of each strategy category. The summary of statistics in the incomplete information setting is generated from the data in the designed environment in Chen \& Sönmez (2006) (shortened as CS 2006). Compared to the earlier study, we combine the small school bias and similar preference bias into the "other" category. Table 4 reports results from proportion of t-tests for each pair of comparison across mechanisms as well as information conditions. We summarize the results below.

Table 4: Comparing proportion of truth-telling across mechanisms and information conditions

\begin{tabular}{|c|c|c|c|c|c|c|c|c|}
\hline \multicolumn{3}{|c|}{ Complete Information } & \multicolumn{3}{|c|}{ Incomplete Information } & \multicolumn{3}{|c|}{ Complete vs. Incomplete } \\
\hline (1) & (2) & (3) & (4) & (5) & (6) & (7) & (8) & (9) \\
\hline Hypotheses & Z-stat & $\mathrm{p}$-value & Hypotheses & z-stat & p-value & Hypotheses & z-stat & p-value \\
\hline$D A_{c}>$ & 4.320 & 00 & $O S_{i}$ & 7.437 & 0.000 & $B O S_{c}$ & 1.390 & 0.165 \\
\hline$T T C_{c}>B O S_{c}$ & 6.196 & 0.000 & $T T C_{i}>B O S_{i}$ & 5.065 & 0.000 & $D A_{c} \neq D A_{i}$ & 2.246 & 0.025 \\
\hline$T T C_{c} \neq D A_{c}$ & 2.066 & 0.039 & $D A_{i} \neq T T C_{i}$ & 2.735 & 0.006 & $T T C_{c} \neq T T C_{i}$ & 2.556 & 0.011 \\
\hline
\end{tabular}

Notes: Z-statistics and p-values are from proportion of t-tests. 
Result 1 (Truth-telling). In the complete information setting, the proportion of truth-telling follows $T T C_{c}>D A_{c}>B O S_{c}$. Comparing each mechanism across information conditions, we find that truth-telling under TTC (BOS) increases (weakly increases) with more information, whereas truth-telling under DA decreases with more information.

Support. Table 4 reports proportion of $t$-tests for each pair of comparison across mechanisms under complete information (column 3), incomplete information (column 6), and across information conditions (column 9).

By Result 1, we reject the null in favor of Hypothesis 1(a) under both complete and incomplete information. That is, the two strategy-proof mechanisms each induce greater proportion of truth-telling than the non-strategy-proof BOS. While we do not anticipate any difference in truth-telling between the two strategy-proof mechanisms, we do find surprisingly significant differences under both complete $\left(T T C_{c}>D A_{c}\right)$ and incomplete information $\left(D A_{i}>T T C_{i}\right)$, albeit in opposite directions, leading us to reject Hypothesis 1(b). As a result of these unexpected differences, we also reject Hypothesis 1(c) that information has no effect on the likelihood of truth-telling for the strategy-proof mechanisms. Specifically, we find that truth-telling under TTC (BOS) increases (weakly increases) with more information, whereas truth-telling under DA decreases with more information.

Compared to prior literature, our complete (incomplete) information setting corresponds to the full (partial) information setting in Pais \& Pintér (2008), respectively. Our mechanism ranking for truth-telling under complete information is consistent with that under full information in Pais \& Pintér (2008). Furthermore, both studies find an increase in truth-telling under TTC from incomplete to complete information, although Pais \& Pintér (2008) find no change in truth-telling under BOS or DA between these two information conditions.

Next, we report aggregate performance of the mechanisms, including efficiency and stability. Following Chen \& Sönmez (2006) and Calsamiglia et al. (2010), we take advantage of the one-shot implementation in our experiments and use the recombinant estimation technique (Mullin \& Reiley, 2006). Based on the theoretical properties of the three mechanisms, we formulate the following hypothesis: 
Hypothesis 2 (Efficiency). (a) The expected per capita payoff will be greater under TTC than under either BOS or DA. (b) The expected per capita payoff under either DA or TTC remains the same when more information is provided.

Again, we are agnostic about the extent to which efficiency under BOS might be affected by changes in information conditions, as it might be context dependent. Nor do we make predictions regarding the efficiency comparisons between BOS and DA. Table 5 reports the recombinant estimation of expected per capita payoffs in the complete (upper panel) and incomplete information setting (lower panel). The recombinant estimation in the incomplete information setting is generated from the CS 2006 data using the same single tie-breaker as that in our complete information treatment. Table 6 presents the t-statistics and p-values from t-tests for efficiency comparisons across mechanisms and information conditions.

Table 5: Recombinant estimation of expected per capita payoffs

\begin{tabular}{llllll}
\hline \hline Mechanism & Mean $(\hat{\mu})$ & Var. $\left(\sigma^{2}\right)$ & Covar. $(\phi)$ & Asym. Var. $(\operatorname{var}(\hat{\mu}))$ & St. dev. \\
\hline$B O S_{c}$ & 11.742 & 0.045 & 0.001 & 0.017 & 0.129 \\
$D A_{c}$ & 11.759 & 0.060 & 0.001 & 0.023 & 0.152 \\
$T T C_{c}$ & 12.255 & 0.029 & 0.001 & 0.014 & 0.120 \\
\hline$B O S_{i}$ & 11.150 & 0.034 & 0.001 & 0.011 & 0.104 \\
$D A_{i}$ & 11.820 & 0.060 & 0.002 & 0.029 & 0.170 \\
$T T C_{i}$ & 11.379 & 0.058 & 0.001 & 0.025 & 0.159 \\
\hline
\end{tabular}

Notes: For a given player, the number of recombination is 200,000. Therefore, the sample size is $14,400,000$ after recombinations. The recombinant estimations for both the complete and incomplete information settings are generated using the same single tie-breaker used in our experiment.

Table 6: Comparing expected per capita payoffs across mechanisms and information conditions

\begin{tabular}{|c|c|c|c|c|c|c|c|c|}
\hline \multicolumn{3}{|c|}{ Complete Information } & \multicolumn{3}{|c|}{ Incomplete Information } & \multicolumn{3}{|c|}{ Complete vs. Incomplete } \\
\hline (1) & (2) & (3) & (4) & (5) & (6) & (7) & (8) & (9) \\
\hline Hypotheses & t-stat & $\mathrm{p}$-value & Hypotheses & t-stat & p-value & Hypotheses & t-stat & p-value \\
\hline$T T C_{c}>B O S_{c}$ & 2.921 & 0.002 & $T T C_{i}>B O S_{i}$ & 1.207 & 0.1 & BOS & 3.580 & 0.000 \\
\hline$T T C_{c}>D A_{c}$ & 2.566 & 0.005 & $T T C_{i}>D A_{i}$ & -1.893 & 0.971 & $D A_{c} \neq D A_{i}$ & 0.270 & 0.787 \\
\hline$B O S_{c} \neq D A_{c}$ & 0.084 & 0.933 & $B O S_{i} \neq D A_{i}$ & 3.364 & 0.001 & $T T C_{c} \neq T T C_{i}$ & 4.400 & 0.000 \\
\hline
\end{tabular}

Notes: T-statistics and p-values are from t-tests. 
Result 2 (Efficiency). Under complete information, the expected per capita payoff follows $T T C_{c}>D A_{c} \sim B O S_{c}$. Comparing each mechanism across information conditions, we find that efficiency under both TTC and BOS increases with more information, whereas efficiency under DA remains unchanged.

Support. Table 6 reports $t$-tests for each pair of comparison across mechanisms under complete information (column 3), incomplete information (column 6 ), and across information conditions (column 9). We report one-sided (twosided) $p$-values for one-sided (two-sided) hypotheses, respectively.

By Result 2, we reject the null in favor of Hypothesis 2(a) under complete information; however, we fail to reject the null under incomplete information. That is, under complete information, TTC achieves greater efficiency than either DA or BOS, whereas under incomplete information, it fails to outperform DA or BOS. Furthermore, we reject Hypothesis 2(b) under TTC but not under DA. In sum, we find that efficiency under both TTC and BOS increases with more information, which is consistent with Result 1 where participants are more likely to tell the truth under complete information. In contrast, additional information has no effect on efficiency under DA.

Our efficiency ranking under complete information is consistent with that under full information in Pais \& Pintér (2008) $\left(T T C_{c}>D A_{c} \sim B O S_{c}\right)$. However, they do not find any statistically significant change in efficiency from partial to full information conditions.

In addition to efficiency, we measure mechanism stability by computing the number of students who have the possibility to block per group, again using recombinant estimation. For simplicity, we call this measure the average number of blocking pairs. Based on the theoretical properties of the three mechanisms, we formulate the following hypothesis:

Hypothesis 3 (Stability). (a) The average number of blocking pairs per group will be lower under DA than under either TTC or BOS. (b) The average number of blocking pairs per group under either DA or TTC remains the same when more information is provided.

In this case, we are silent on the comparison between TTC and BOS, as well as stability under BOS across information conditions, as these comparisons depends on the specific environment. Table 7 reports the results of recombinant estimation in the number of justified envy per group under complete (upper panel) and incomplete information (lower panel). The results under incomplete 
information is generated from the CS 2006 data, using the same single tiebreaker as in our complete information setting.

Table 7: Recombinant estimation of average number of blocking pairs per group

\begin{tabular}{llllll}
\hline \hline Mechanism & Mean $(\hat{\mu})$ & Var. $\left(\sigma^{2}\right)$ & Covar. $(\phi)$ & Asym. Var. $(\operatorname{var}(\hat{\mu}))$ & St. dev. \\
\hline BOS $_{c}$ & 9.354 & 4.935 & 0.088 & 1.589 & 1.261 \\
$D A_{c}$ & 2.906 & 0.523 & 0.012 & 0.210 & 0.459 \\
$T T C_{c}$ & 10.624 & 3.737 & 0.085 & 1.524 & 1.234 \\
\hline BOS $_{i}$ & 14.323 & 4.449 & 0.098 & 1.757 & 1.326 \\
$D A_{i}$ & 2.500 & 1.250 & 0.035 & 0.629 & 0.793 \\
$T T C_{i}$ & 12.461 & 5.839 & 0.095 & 1.718 & 1.311 \\
\hline
\end{tabular}

Notes: For a given player, the number of recombination is 200,000 . Therefore, the sample size is $14,400,000$ after recombinations. The recombinant estimations for both the complete and incomplete information settings are generated using the same single tie-breaker used in our experiment.

Result 3 (Stability). Under both complete and incomplete information, the average number of blocking pairs per group follows $D A<B O S \sim T T C$. Comparing each mechanism across information conditions, we find that the average number of blocking pairs per group under BOS decreases with more information, whereas that under either DA or TTC is largely unchanged.

Support. Table 8 reports $t$-tests for each pair of comparison across mechanisms under complete information (column 3), incomplete information (column 6), and across information conditions (column 9). We report one-sided (twosided) p-values for one-sided (two-sided) hypotheses, respectively.

Table 8: Comparing average number of blocking pairs per group across mechanisms and information conditions

\begin{tabular}{|c|c|c|c|c|c|c|c|c|}
\hline \multicolumn{3}{|c|}{ Complete Information } & \multicolumn{3}{|c|}{ Incomplete Information } & \multicolumn{3}{|c|}{ Complete vs. Incomplete } \\
\hline (1) & (2) & (3) & (4) & (5) & (6) & (7) & (8) & (9) \\
\hline Hypotheses & t-stat & p-value & Hypotheses & t-stat & $\mathrm{p}$-value & Hypotheses & t-stat & p-value \\
\hline$B O S_{c}$ & 4.807 & 0.000 & BOS & 7.655 & 0.000 & $B O S_{c}$ & 2.716 & 0.007 \\
\hline$T T C_{c}>D A_{c}$ & 5.861 & 0.000 & $T T C_{i}>D A_{i}$ & 6.503 & 0.000 & $D A_{c} \neq D A_{i}$ & 0.444 & 0.657 \\
\hline$T T C_{c} \neq B O S_{c}$ & 0.720 & 0.472 & $T T C_{i} \neq B O S_{i}$ & 0.999 & 0.318 & $T T C_{c} \neq T T C_{i}$ & 1.020 & 0.308 \\
\hline
\end{tabular}

Notes: T-statistics and p-values are from t-tests. 
By Result 3, we reject the null in favor of Hypothesis 3(a). That is, DA is more stable than either TTC or BOS under both complete and incomplete information. However, we fail to reject Hypothesis 3(b) that the two strategy-proof mechanisms generate the same number of blocking pairs across information conditions. Lastly, unpredicted by theory, we find that BOS becomes more stable with more information.

Compared to the prior experimental literature on school choice, our stability ranking among the three mechanisms under incomplete information is identical to that in the untruncated treatment in Calsamiglia et al. (2010) as well as that in the partial information treatment in Pais \& Pintér (2008). In comparison, our stability ranking among the three mechanisms under complete information is directionally consistent with the corresponding ranking under full information (DA $\geq$ TTC) in Pais \& Pintér (2008), although the latter is not statistically significant. Lastly, our finding that the stability of BOS improves with more information is again directionally consistent with the corresponding result in Pais \& Pintér (2008), who report a 33 percentage point increase in the proportion of stable outcomes under BOS from partial to full information, but this difference is statistically insignificant in their study.

\section{CONCLUSION}

In this paper, we investigate the performance of three influential school choice mechanisms under complete information, and compare that with the performance of the same three mechanisms under incomplete information (Chen \& Sönmez, 2006). Overall, we find that information has significant effects on the performance of school choice mechanisms.

Specifically, we find that, under complete information, TTC outperforms both DA and BOS in terms of truth-telling and efficiency, whereas DA is more stable than either TTC or BOS regardless of information conditions. Compared to the incomplete information setting in Chen \& Sönmez (2006), of the two strategy-proof mechanisms, more information increases both truth-telling and efficiency under TTC, and reduces truth-telling under DA. In comparison, more information increases truthful preference revelation, stability and efficiency under BOS.

Findings from this paper and prior school choice experiments point to several policy implications. First, in real life implementations, truth-telling is not verifiable. However, a designer can advise students and parents to reveal 
their preferences truthfully if the mechanism is strategy-proof. We also see that, regardless of the information condition, a strategy-proof mechanism always outperforms the manipulable BOS in truth-telling, stability or efficiency. Therefore, a strategy-proof mechanism, such as DA or TTC, should be preferred to the manipulable BOS.

Second, of the two strategy-proof mechanisms, which one should be chosen? Our results suggest that the answer depends on whether the policy-makers put more weight on stability or efficiency. If stability is valued above efficiency, DA should be chosen. Otherwise, TTC is the clear choice. In practice, we see that both mechanisms have been chosen as a replacement for BOS.

Lastly, unpredicted by theory, we find that information provision improves the aggregate performance of both TTC and BOS. In real life, information acquisition is likely to be costly. Under this more realistic scenario, information provision by education authorities is likely to have even greater welfare gains (Chen \& He, 2016). Therefore, our results suggest that education authorities should provide more information about the environment to improve the performance of either the manipulable BOS or a strategy-proof alternative, such as the TTC.

\section{Supplement: Experimental Instructions}

The complete instructions for subject \#1 under BOS (Mechanism B) are shown here. Instructions for all other subjects are identical except the individual portion of the payoff table. Instructions for DA (Mechanism G) and TTC (Mechanism T) are identical to those for BOS except the "Allocation Method" and "An Example" sections, hence only those sections are shown here.

\section{Instructions - Mechanism B}

This is an experiment in the economics of decision making. The instructions are simple, and if you follow them carefully and make good decisions, you might earn a considerable amount of money. In this experiment, we simulate a procedure to allocate students to schools. The procedure, payment rules, and student allocation method are described below. Do not communicate with each other during the experiment. If you have questions at any point during the experiment, raise your hand and the experimenter will help you.

\section{Procedure}

- There are 36 participants in this experiment. You are participant \#1. 
- In this simulation, 36 school slots are available across seven schools. These schools differ in size, geographic location, specialty, and quality of instruction in each specialty. Each school slot is allocated to one participant. There are three slots each at schools A and B, and six slots each at schools C, D, E, F and G.

- Your payoff amount depends on the school slot you hold at the end of the experiment. Payoff amounts are outlined in the following table. These amounts reflect the desirability of the school in terms of location, specialty and quality of instruction.

\begin{tabular}{c|rrrrrrr} 
Slot received at School: & A & B & C & D & E & F & G \\
\hline Payoff to Participant \#1 (in dollars) & 13 & 16 & 9 & 2 & 5 & 11 & 7 \\
\hline
\end{tabular}

The table is explained as follows:

- You will be paid \$13 if you hold a slot at school A at the end of the experiment.

- You will be paid \$16 if you hold a slot at school B at the end of the experiment.

- You will be paid $\$ 9$ if you hold a slot at school $\mathrm{C}$ at the end of the experiment.

- You will be paid \$2 if you hold a slot at school D at the end of the experiment.

- You will be paid $\$ 5$ if you hold a slot at school $\mathrm{E}$ at the end of the experiment.

- You will be paid \$11 if you hold a slot at school $\mathrm{F}$ at the end of the experiment.

- You will be paid \$7 if you hold a slot at school G at the end of the experiment.

*NOTE* different participants have different payoff tables. That is, payoff by school is different for different participants.

- During the experiment, each participant first completes the Decision Sheet by indicating school preferences. Note that you need to rank all seven schools in order to indicate your preferences.

- After all participants have completed their Decision Sheets, the experimenter collects the Sheets and starts the allocation process.

- Once the allocations are determined, the experimenter informs each participants of his/her allocation slot and respective payoff.

\section{The payoff table for all 36 students:}

\section{Allocation Method}

- In this experiment, participants are defined as belonging to the following school districts.

Participants \#1 - \#3 live within the school district of school A, Participants \#4 - \#6 live within the school district of school B, Participants \#7 - \#12 live within the school district of school C, Participants \#13 - \#18 live within the school district of school D, Participants \#19 - \#24 live within the school district of school E, Participants \#25 - \#30 live within the school district of school F, Participants \#31 - \#36 live within the school district of school G. 


\begin{tabular}{crrrrrrr}
\hline \hline & \multicolumn{7}{c}{ Schools } \\
\cline { 2 - 7 } Student ID & A & B & C & D & E & F & G \\
\hline 1 & $\mathbf{1 3}$ & 16 & 9 & 2 & 5 & 11 & 7 \\
2 & $\mathbf{1 6}$ & 13 & 11 & 7 & 2 & 5 & 9 \\
3 & $\mathbf{1 1}$ & 13 & 7 & 16 & 2 & 9 & 5 \\
\hline 4 & 16 & $\mathbf{1 3}$ & 11 & 5 & 2 & 7 & 9 \\
5 & 11 & $\mathbf{1 6}$ & 2 & 5 & 13 & 7 & 9 \\
6 & 16 & $\mathbf{1 3}$ & 7 & 9 & 11 & 2 & 5 \\
\hline 7 & 13 & 16 & $\mathbf{9}$ & 5 & 11 & 7 & 2 \\
8 & 16 & 9 & $\mathbf{1 1}$ & 2 & 13 & 7 & 5 \\
9 & 16 & 13 & $\mathbf{2}$ & 5 & 9 & 7 & 11 \\
10 & 16 & 7 & $\mathbf{9}$ & 5 & 2 & 11 & 13 \\
11 & 7 & 16 & $\mathbf{1 1}$ & 9 & 5 & 2 & 13 \\
12 & 13 & 16 & $\mathbf{9}$ & 11 & 2 & 7 & 5 \\
\hline 13 & 9 & 16 & 2 & $\mathbf{1 3}$ & 11 & 5 & 7 \\
14 & 16 & 5 & 2 & $\mathbf{9}$ & 7 & 13 & 11 \\
15 & 13 & 16 & 9 & $\mathbf{1 1}$ & 2 & 7 & 5 \\
16 & 16 & 13 & 11 & $\mathbf{5}$ & 9 & 7 & 2 \\
17 & 13 & 16 & 5 & $\mathbf{7}$ & 2 & 9 & 11 \\
18 & 16 & 13 & 5 & $\mathbf{9}$ & 7 & 11 & 2 \\
\hline 19 & 11 & 16 & 7 & 5 & $\mathbf{1 3}$ & 9 & 2 \\
20 & 16 & 13 & 7 & 9 & $\mathbf{5}$ & 2 & 11 \\
21 & 13 & 16 & 2 & 7 & $\mathbf{9}$ & 11 & 5 \\
22 & 16 & 11 & 7 & 2 & $\mathbf{9}$ & 5 & 13 \\
23 & 16 & 13 & 7 & 2 & $\mathbf{5}$ & 11 & 9 \\
24 & 16 & 13 & 11 & 5 & $\mathbf{9}$ & 2 & 7 \\
\hline 25 & 13 & 16 & 2 & 5 & 11 & $\mathbf{9}$ & 7 \\
26 & 16 & 13 & 5 & 9 & 7 & $\mathbf{2}$ & 11 \\
27 & 7 & 11 & 5 & 2 & 13 & $\mathbf{9}$ & 16 \\
28 & 16 & 13 & 7 & 2 & 11 & $\mathbf{5}$ & 9 \\
29 & 7 & 11 & 16 & 13 & 2 & $\mathbf{9}$ & 5 \\
30 & 16 & 9 & 7 & 2 & 5 & $\mathbf{1 1}$ & 13 \\
\hline 31 & 11 & 16 & 7 & 2 & 5 & 9 & $\mathbf{1 3}$ \\
32 & 13 & 9 & 16 & 2 & 5 & 7 & $\mathbf{1 1}$ \\
33 & 13 & 16 & 11 & 9 & 7 & 5 & $\mathbf{2}$ \\
34 & 16 & 11 & 2 & 7 & 5 & 13 & $\mathbf{9}$ \\
35 & 7 & 16 & 2 & 5 & 11 & 13 & $\mathbf{9}$ \\
36 & 16 & 13 & 5 & 7 & 9 & 2 & $\mathbf{1 1}$ \\
\hline \hline & & & & & & &
\end{tabular}


- In addition, for each school, a separate priority order of the students is determined as follows:

- Highest Priority Level: Participants who rank the school as their first choice AND who also live within the school district.

- 2nd Priority Level: Participants who rank the school as their first choice BUT who do not live within the school district.

- 3rd Priority Level: Participants who rank the school as their second choice AND who also live within the school district.

- 4th Priority Level: Participants who rank the school as their second choice BUT who do not live within the school district.

- 13th Priority Level: Participants who rank the school as their seventh choice AND who also live within the school district.

- Lowest Priority Level: Participants who rank the school as their seventh choice BUT who do not live within the school district.

- The ties between participants at the same priority level are broken using a fair lottery. This means each participant has an equal chance of being the first in the line, the second in the line, $\cdots$, as well as the last in the line. To determine this fair lottery, a participant will be asked to draw 36 ping pong balls from an urn, one at a time. Each ball has a number on it, corresponding to a participant ID number. The sequence of the draw determines the order in the lottery.

- Therefore, to determine the priority order of a student for a school:

- The first consideration is how highly the participant ranks the school in his/her Decision Sheet,

- The second consideration is whether the participant lives within the school district or not, and

- The last consideration is the order in the fair lottery.

- Once the priorities are determined, slots are allocated in seven rounds.

Round 1. a. An application to the first ranked school in the Decision Sheet is sent for each participant.

b. Each school accepts the students with higher priority order until all slots are filled. These students and their assignments are removed from the system. The remaining applications for each respective school are rejected. 
Round 2. a. The rejected applications are sent to his/her second ranked school in the Decision Sheet.

b. If a school still has available slots remaining from Round 1, then it accepts the students with higher priority order until all slots are filled. The remaining applications are rejected.

Round 6. a. The application of each participant who is rejected by his/her top five choices is sent to his/her sixth choice.

b. If a school still has slots available, then it accepts the students with higher priority order until all slots are filled. The remaining applications are rejected.

Round 7. Each remaining participant is assigned a slot at his/her last choice.

\section{An Example:}

We will go through a simple example to illustrate how the allocation method works.

Students and Schools: In this example, there are six students, 1-6, and four schools, Clair, Erie, Huron and Ontario.

Student ID Number: 1, 2,3,4,5,6 Schools: Clair, Erie, Huron, Ontario

Slots and Residents: There are two slots each at Clair and Erie, and one slot each at Huron and Ontario. Residents of districts are indicated in the table below.

\begin{tabular}{|c|c|c|c|}
\hline School & Slot 1 & Slot 2 & District Residents \\
\hline Clair & $\square$ & \begin{tabular}{|l} 
\\
\end{tabular} & 1 \\
\hline Erie & & & 34 \\
\hline Huron & 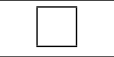 & & 5 \\
\hline Ontario & $\square$ & & 6 \\
\hline
\end{tabular}

Lottery: The lottery produces the following order.

$$
1-2-3-4-5-6
$$

Submitted School Rankings: The students submit the following school rankings: 


\begin{tabular}{l|llll} 
& $\begin{array}{l}\text { 1st } \\
\text { Choice }\end{array}$ & $\begin{array}{l}\text { 2nd } \\
\text { Choice }\end{array}$ & $\begin{array}{l}\text { 3rd } \\
\text { Choice }\end{array}$ & $\begin{array}{l}\text { Last } \\
\text { Choice }\end{array}$ \\
\hline Student 1 & Huron & Clair & Ontario & Erie \\
\hline Student 2 & Huron & Ontario & Clair & Erie \\
\hline Student 3 & Ontario & Clair & Erie & Huron \\
\hline Student 4 & Huron & Clair & Ontario & Erie \\
\hline Student 5 & Ontario & Huron & Clair & Erie \\
\hline Student 6 & Clair & Erie & Ontario & Huron \\
\hline
\end{tabular}

Priority: School priorities depend on: (1) how highly the student ranks the school, (2) whether the school is a district school, and (3) the lottery order.

Clair : Student 6 ranks Clair first. Students 1, 3 and 4 rank Clair second; among them, student 1 lives within the Clair school district. Students 2 and 5 rank Clair third. Using the lottery order to break ties, the priority order for Clair is 6-1-3-4-2-5.

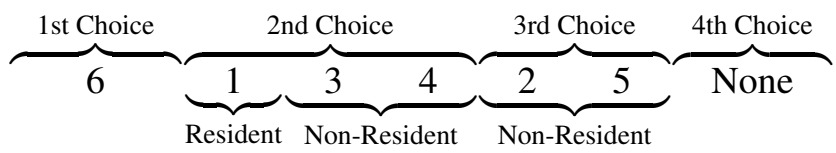

Erie : Student 6 ranks Erie second. Student 3 ranks Erie third. Students 1, 2, 4 and 5 rank Erie fourth; among them student 4 lives within the Erie school district. Using the lottery order to break ties, the priority for Erie is 6-3-4-1-2-5.

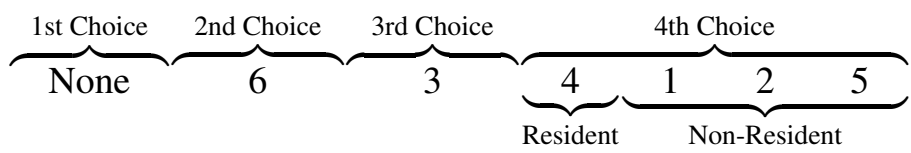

Huron : Students 1, 2 and 4 rank Huron first. Student 5 ranks Huron second. Students 3 and 6 rank Huron fourth. Using the lottery order to break ties, the priority for Huron is 1-2-4-5-3-6.

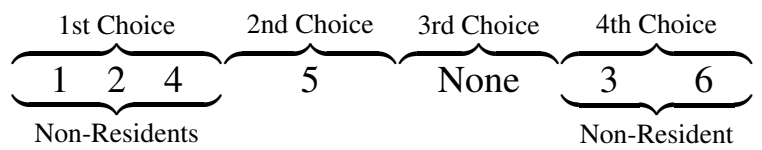


Ontario : Students 3 and 5 rank Ontario first. Student 2 ranks Ontario second. Students 1, 4 and 6 rank Ontario third; among them student 6 lives within the Ontario school district. Using the lottery order to break ties, the priority for Ontario is 3-5-2-6-1-4.

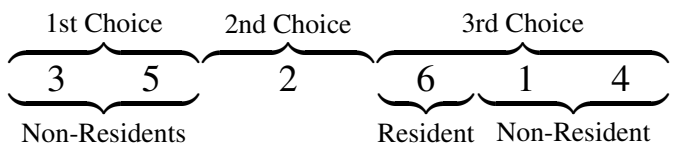

Allocation: This allocation method consists of the following rounds.

Round 1 : Each student applies to his/her first choice: Students 1, 2 and 4 apply to Huron,

students 3 and 5 apply to Ontario and student 6 applies to Clair.

- School Clair accepts Student 6.

- School Huron accepts Student 1 and rejects Students 2,4.

- School Ontario accepts Student 3 and rejects Student 5.

\begin{tabular}{cl|c|cccc|cc} 
Applicants & & School & & Accept & Reject & & Slot 1 & Slot 2 \\
\hline 6 & $\longrightarrow$ & Clair & $\longrightarrow$ & 6 & & $\longrightarrow$ & 6 & $\square$ \\
$1,2,4$ & $\longrightarrow$ & Erie & $\longrightarrow$ & & & $\longrightarrow$ & $\square$ & $\square$ \\
3,5 & $\longrightarrow$ & Huron & $\longrightarrow$ & 1 & 2,4 & $\longrightarrow$ & 1 & - \\
\hline
\end{tabular}

Accepted students are removed from the subsequent process.

Round 2 : Each student who is rejected in Round 1 then applies to his/her second choice: Student 2 applies to Ontario, student 4 applies to Clair, and student 5 applies to Huron.

- No slot is left at Ontario, so it rejects student 2.

- Clair accepts student 4 for its last slot.

- No slot is left at Huron, so it rejects student 5.

\begin{tabular}{|c|c|c|c|c|c|c|c|c|}
\hline Applicants & & School & & Accept & Reject & & Slot 1 & Slot 2 \\
\hline 4 & $\longrightarrow$ & Clair & $\longrightarrow$ & 4 & & $\longrightarrow$ & 6 & \begin{tabular}{|l|}
44 \\
\end{tabular} \\
\hline & $\longrightarrow$ & Erie & $\longrightarrow$ & & & $\longrightarrow$ & & 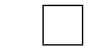 \\
\hline 5 & $\longrightarrow$ & Huron & $\longrightarrow$ & & 5 & $\longrightarrow$ & 1 & - \\
\hline 2 & $\longrightarrow$ & Ontario & $\longrightarrow$ & & 2 & $\longrightarrow$ & 3 & - \\
\hline
\end{tabular}


Round 3 : Each student who is rejected in Rounds 1-2 applies to his/her third choice: Students 2 and 5 apply to Clair.

- No slot is left at Clair, so it rejects students 2 and 5.

\begin{tabular}{|c|c|c|c|c|c|c|c|c|}
\hline Applicants & & School & & Accept & Reject & & Slot 1 & Slot 2 \\
\hline \multirow[t]{4}{*}{2,5} & $\longrightarrow$ & Clair & $\longrightarrow$ & & 2,5 & $\longrightarrow$ & 6 & 4 \\
\hline & $\longrightarrow$ & Erie & $\longrightarrow$ & & & $\longrightarrow$ & 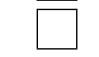 & $\square$ \\
\hline & $\longrightarrow$ & Huron & $\longrightarrow$ & & & $\longrightarrow$ & 1 & - \\
\hline & $\longrightarrow$ & Ontario & $\longrightarrow$ & & & $\longrightarrow$ & 3 & - \\
\hline
\end{tabular}

Round 4 : Each remaining student is assigned a slot at his/her last choice:

Students 2 and 5 receive a slot at Erie.

\begin{tabular}{|c|c|c|c|c|c|c|c|}
\hline Applicant & & School & & Accept & Reject & Slot 1 & Slot 2 \\
\hline \multirow{4}{*}{2,5} & $\longrightarrow$ & Clair & $\longrightarrow$ & \multirow{4}{*}{2,5} & $\longrightarrow$ & 6 & 4 \\
\hline & $\longrightarrow$ & Erie & $\longrightarrow$ & & $\longrightarrow$ & 2 & 5 \\
\hline & $\longrightarrow$ & Huron & $\longrightarrow$ & & $\longrightarrow$ & 1 & - \\
\hline & $\longrightarrow$ & Ontario & $\longrightarrow$ & & $\longrightarrow$ & 3 & - \\
\hline
\end{tabular}

Based on this method, the final allocations are:

\begin{tabular}{c|cccccc} 
Student & 1 & 2 & 3 & 4 & 5 & 6 \\
\hline School & Huron & Erie & Ontario & Clair & Erie & Clair
\end{tabular}

You will have 15 minutes to go over the instructions at your own pace, and make your decisions. Feel free to earn as much cash as you can. Are there any questions?

\section{Decision Sheet - Mechanism B}

- Recall: You are participant \#1 and you live within the school district of School A.

- Recall: Your payoff amount depends on the school slot you hold at the end of the experiment. Payoff amounts are outlined in the following table.

\begin{tabular}{l|ccccccc} 
School: & A & B & C & D & E & F & G \\
\hline Payoff in dollars & 13 & 16 & 9 & 2 & 5 & 11 & 7 \\
\hline
\end{tabular}


You will be paid $\$ 13$ if you hold a slot of School A at the end of the experiment. You will be paid $\$ 16$ if you hold a slot of School B at the end of the experiment. You will be paid $\$ 9$ if you hold a slot of School $\mathrm{C}$ at the end of the experiment. You will be paid $\$ 2$ if you hold a slot of School D at the end of the experiment. You will be paid $\$ 5$ if you hold a slot of School E at the end of the experiment. You will be paid $\$ 11$ if you hold a slot of School $\mathrm{F}$ at the end of the experiment. You will be paid $\$ 7$ if you hold a slot of School $\mathrm{G}$ at the end of the experiment.

Please write down your ranking of the schools (A through G) from your first choice to your last choice. Please rank ALL seven schools.

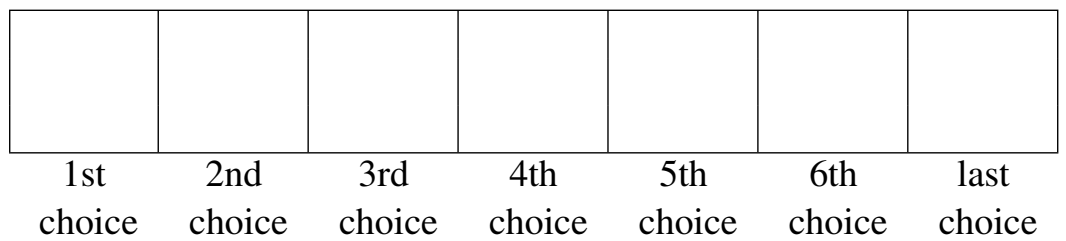

Your I.D : \#1 Your Name (print):

This is the end of the experiment for you. Please remain seated until the experimenter collects your Decision Sheet. Thank you.

The lottery, as well as all participants' rankings will be entered into a computer after the experiment. The experimenter will inform each participants of his/her allocation slot and respective payoff once it is computed.

Session Number : $1 \quad$ Mechanism $1 \quad$ Payoff Matrix 1

\section{Instructions - Mechanism G}

\section{Allocation Method}


- In this experiment, participants are defined as belonging to the following school districts.

- Participants \#1 - \#3 live within the school district of school A,

- Participants \#4 - \#6 live within the school district of school B,

- Participants \#7 - \#12 live within the school district of school C,

- Participants \#13 - \#18 live within the school district of school D,

- Participants \#19 - \#24 live within the school district of school E,

- Participants \#25 - \#30 live within the school district of school F,

- Participants \#31 - \#36 live within the school district of school G.

- A priority order is determined for each school. Each participant is assigned a slot at the best possible school reported in his/her Decision Sheet that is consistent with the priority order below.

- The priority order for each school is separately determined as follows:

- High Priority Level: Participants who live within the school district. Since the number of High priority participants at each school is equal to the school capacity, each High priority participant is guaranteed an assignment which is at least as good as his/her district school based on the ranking indicated in his/her Decision Sheet.

- Low Priority Level: Participants who do not live within the school district.

The priority among the Low priority students is based on their respective order in a fair lottery. This means each participant has an equal chance of being the first in the line, the second in the line, $\cdots$, as well as the last in the line. To determine this fair lottery, a participant will be asked to draw 36 ping pong balls from an urn, one at a time. Each ball has a number on it, corresponding to a participant ID number. The sequence of the draw determines the order in the lottery.

- Once the priorities are determined, the allocation of school slots is obtained as follows:

- An application to the first ranked school in the Decision Sheet is sent for each participant. 
- Throughout the allocation process, a school can hold no more applications than its number of slots.

If a school receives more applications than its capacity, then it rejects the students with lowest priority orders. The remaining applications are retained.

- Whenever an applicant is rejected at a school, his application is sent to the next highest school on his Decision Sheet.

- Whenever a school receives new applications, these applications are considered together with the retained applications for that school. Among the retained and new applications, the lowest priority ones in excess of the number of the slots are rejected, while remaining applications are retained.

- The allocation is finalized when no more applications can be rejected.

Each participant is assigned a slot at the school that holds his/her application at the end of the process.

\section{An Example:}

We will go through a simple example to illustrate how the allocation method works.

Students and Schools: In this example, there are six students, 1-6, and four schools, Clair, Erie, Huron and Ontario.

Student ID Number: 1,2,3,4,5,6 Schools: Clair, Erie, Huron, Ontario

Slots and Residents: There are two slots each at Clair and Erie, and one slot each at Huron and Ontario. Residents of districts are indicated in the table below.

\begin{tabular}{|c|c|c|c|}
\hline School & Slot 1 & Slot 2 & District Residents \\
\hline Clair & $\square$ & $\square$ & 1 \\
\hline Erie & $\square$ & $\square$ & 3 \\
\hline Huron & $\square$ & & 5 \\
\hline Ontario & $\square$ & & 6 \\
\hline
\end{tabular}

Lottery: The lottery produces the following order.

$$
1-2-3-4-5-6
$$


Submitted School Rankings: The students submit the following school rankings:

\begin{tabular}{l|llll} 
& $\begin{array}{l}\text { 1st } \\
\text { Choice }\end{array}$ & $\begin{array}{l}\text { 2nd } \\
\text { Choice }\end{array}$ & $\begin{array}{l}\text { 3rd } \\
\text { Choice }\end{array}$ & $\begin{array}{l}\text { Last } \\
\text { Choice }\end{array}$ \\
\hline Student 1 & Huron & Clair & Ontario & Erie \\
\hline Student 2 & Huron & Ontario & Clair & Erie \\
\hline Student 3 & Ontario & Clair & Erie & Huron \\
\hline Student 4 & Huron & Clair & Ontario & Erie \\
\hline Student 5 & Ontario & Huron & Clair & Erie \\
\hline Student 6 & Clair & Erie & Ontario & Huron \\
\hline
\end{tabular}

Priority : School priorities first depend on whether the school is a district school, and next on the lottery order:

\begin{tabular}{|c|c|c|}
\hline & $\overbrace{\overbrace{}^{\text {Resident }}}$ & Non-Resident \\
\hline & 1,2 & $3-4$ \\
\hline & 3,4 & 1 \\
\hline Prio & 5 & $-1-2-3-4-$ \\
\hline Priority order at Ontario: & 6 & $-1-2-3-4-5$ \\
\hline
\end{tabular}

\section{The allocation method consists of the following steps:}

Step 1 : Each student applies to his/her first choice: students 1, 2 and 4 apply to Huron, students 3 and 5 apply to Ontario, and student 6 applies to Clair.

- Clair holds the application of student 6 .

- Huron holds the application of student 1 and rejects students 2 and 4.

- Ontario holds the application of student 3 and rejects student 5.

\begin{tabular}{|c|c|c|c|c|c|}
\hline Applicant & & School & & Hold & Reject \\
\hline 6 & $\longrightarrow$ & Clair & $\longrightarrow$ & \begin{tabular}{|l|}
6 \\
\end{tabular} & \\
\hline & $\longrightarrow$ & Erie & $\longrightarrow$ & & \\
\hline $1,2,4$ & $\longrightarrow$ & Huron & $\longrightarrow$ & $1-$ & 2,4 \\
\hline 3,5 & $\longrightarrow$ & Ontario & $\longrightarrow$ & $3-$ & 5 \\
\hline
\end{tabular}


Step 2 : Each student rejected in Step 1 applies to his/her next choice: student 2 applies to Ontario, student 4 applies to Clair, and student 5 applies to Huron.

- Clair considers the application of student 4 together with the application of student 6 , which was on hold. It holds both applications.

- Huron considers the application of student 5 together with the application of student 1 , which was on hold. It holds the application of student 5 and rejects student 1 .

- Ontario considers the application of student 2 together with the application of student 3 , which was on hold. It holds the application of student 2 and rejects student 3 .

\begin{tabular}{|c|c|c|c|c|c|c|c|}
\hline Hold & \multicolumn{2}{|l|}{ New applicants } & School & \multicolumn{3}{|c|}{ Hold } & Reject \\
\hline 6 & 4 & $\longrightarrow$ & Clair & $\longrightarrow$ & 6 & 4 & \\
\hline & & $\longrightarrow$ & Erie & $\longrightarrow$ & & & \\
\hline 1 & 5 & $\longrightarrow$ & Huron & $\longrightarrow$ & 5 & - & 1 \\
\hline $3-$ & 2 & $\longrightarrow$ & Ontario & $\longrightarrow$ & 2 & - & 3 \\
\hline
\end{tabular}

Step 3 : Each student rejected in Step 2 applies to his/her next choice: Students 1 and 3 apply to Clair.

- Clair considers the applications of students 1 and 3 together with the applications of students 4 and 6 , which were on hold. It holds the applications of students 1 and 3 and rejects students 4 and 6 .

\begin{tabular}{|c|c|c|c|c|c|c|c|}
\hline Hold & New applicants & & School & \multicolumn{3}{|c|}{ Hold } & Reject \\
\hline \begin{tabular}{|l|l|}
6 & 4 \\
\end{tabular} & 1,3 & $\longrightarrow$ & Clair & $\longrightarrow$ & & 3 & 4,6 \\
\hline & & $\longrightarrow$ & Erie & $\longrightarrow$ & & 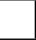 & \\
\hline $5-$ & & $\longrightarrow$ & Huron & $\longrightarrow$ & 5 & - & \\
\hline $2-$ & & $\longrightarrow$ & Ontario & $\longrightarrow$ & 2 & - & \\
\hline
\end{tabular}

Step 4 : Each student rejected in Step 3 applies to his/her next choice: Student 4 applies to Ontario and student 6 applies to Erie.

- Ontario considers the application of student 4 together with the application of student 2, which was on hold. It holds the application of student 2 and rejects student 4 .

- Erie holds the application of student 6. 


\begin{tabular}{|c|c|c|c|c|c|c|}
\hline Hold & New applicants & & School & & Hold & Reject \\
\hline \begin{tabular}{|l|l|}
1 & 3 \\
\end{tabular} & & $\longrightarrow$ & Clair & $\longrightarrow$ & \begin{tabular}{l|l|}
1 & 3 \\
\end{tabular} & \\
\hline & 6 & $\longrightarrow$ & Erie & $\longrightarrow$ & 6 & \\
\hline $5-$ & & $\longrightarrow$ & Huron & $\longrightarrow$ & \begin{tabular}{|l|}
$5-$ \\
\end{tabular} & \\
\hline $2-$ & 4 & $\longrightarrow$ & Ontario & $\longrightarrow$ & 2 - & 4 \\
\hline
\end{tabular}

Step 5 : Each student rejected in Step 4 applies to his/her next choice: student 4 applies to Erie.

- Erie considers the application of student 4 together with the application of student 6 , which was on hold. It holds both applications.

\begin{tabular}{|c|c|c|c|c|c|c|}
\hline Hold & New applicants & & School & & Hold & Reject \\
\hline \begin{tabular}{|l|l|}
1 & 3 \\
\end{tabular} & \multirow{4}{*}{4} & $\longrightarrow$ & Clair & $\longrightarrow$ & \begin{tabular}{|l||l|}
1 & 3 \\
\end{tabular} & \\
\hline 6 & & $\longrightarrow$ & Erie & $\longrightarrow$ & \begin{tabular}{|l|l|}
6 & 4 \\
\end{tabular} & \\
\hline $5-$ & & $\longrightarrow$ & Huron & $\longrightarrow$ & $5-$ & \\
\hline $2-$ & & $\longrightarrow$ & Ontario & $\longrightarrow$ & $2-$ & \\
\hline
\end{tabular}

No application is rejected at Step 5. Based on this method, the final allocations are:

\begin{tabular}{c|cccccc} 
Student & 1 & 2 & 3 & 4 & 5 & 6 \\
\hline School & Clair & Ontario & Clair & Erie & Huron & Erie
\end{tabular}

\section{Instructions - Mechanism T}

\section{Allocation Method}

- In this experiment, participants are defined as belonging to the following school districts.

- Participants \#1 - \#3 live within the school district of school A,

- Participants \#4 - \#6 live within the school district of school B,

- Participants \#7 - \#12 live within the school district of school C,

- Participants \#13 - \#18 live within the school district of school D, 
- Participants \#19 - \#24 live within the school district of school E,

- Participants \#25 - \#30 live within the school district of school F,

- Participants \#31 - \#36 live within the school district of school G.

- Each participant is first tentatively assigned to the school within his/her respective district. Next, Decision Sheet rankings are used to determine mutually beneficial exchanges between two or more participants. The order in which these exchanges are considered is determined by a fair lottery. This means each participant has an equal chance of being the first in the line, the second in the line, $\cdots$, as well as the last in the line. To determine this fair lottery, a participant will be asked to draw 36 ping pong balls from an urn, one at a time. Each ball has a number on it, corresponding to a participant ID number. The sequence of the draw determines the order in the lottery.

- The specific allocation process is explained below.

- Initially all slots are available for allocation.

- All participants are ordered in a queue based on the order in the lottery.

- Next, an application to the highest ranked school in the Decision Sheet is submitted for the participant at the top of the queue.

* If the application is submitted to his district school, then his tentative assignment is finalized (thus he is assigned a slot at his district school). The participant and his assignment are removed from subsequent allocations. The process continues with the next participant in line.

* If the application is submitted to another school, say school $S$, then the first participant in the queue who tentatively holds a slot at School $S$ is moved to the top of the queue directly in front of the requester.

- Whenever the queue is modified, the process continues similarly: An application is submitted to the highest ranked school with available slots for the participant at the top of the queue.

* If the application is submitted to his district school, then his tentative assignment is finalized. The process continues with the next participant in line.

* If the application is submitted to another school, say school $S$, then the first participant in the queue who tentatively holds a slot at school $S$ is moved to the top of the queue directly in front of the requester. 
This way, each participant is guaranteed an assignment which is at least as good as his/her district school based on the preferences indicated in his/her Decision Sheet.

- A mutually-beneficial exchange is obtained when a cycle of applications are made in sequence, which benefits all affected participants, e.g., I apply to John's district school, John applies to your district school, and you apply to my district school. In this case, the exchange is completed and the participants as well as their assignments are removed from subsequent allocations.

- The process continues until all participants are assigned a school slot.

\section{An Example:}

We go through a simple example to illustrate how the allocation method works.

Students and Schools: In this example, there are six students, 1-6, and four schools, Clair, Erie, Huron and Ontario.

Student ID Number: 1, 2,3,4,5,6 Schools: Clair, Erie, Huron, Ontario

Slots and Residents: There are two slots each at Clair and Erie, and one slot each at Huron and Ontario. Residents of districts are indicated in the table below.

\begin{tabular}{r|ccc} 
School & Slot 1 & Slot 2 & District Residents \\
\hline Clair & $\square$ & $\square$ & $1 \quad 2$ \\
\hline Erie & $\square$ & $\square$ & $3 \quad 4$ \\
\hline Huron & $\square$ & 5 \\
\hline Ontario & $\square$ & 6 \\
\hline
\end{tabular}

Tentative assignments: Students are tentatively assigned slots at their district schools.

\begin{tabular}{c|ccl} 
School & \multicolumn{3}{|l}{ Slot 1 Slot 2} \\
\hline Clair & 1 & 2 & Students 1 and 2 are tentatively assigned a slot at Clair; \\
Erie & 3 & 4 & Students 3 and 4 are tentatively assigned a slot at Erie; \\
Huron & 5 & - & Student 5 is tentatively assigned a slot at Huron; \\
Ontario & 6 & - & Students 6 is tentatively assigned a slot at Ontario. \\
\hline
\end{tabular}


Lottery: The lottery produces the following order.

$$
1-2-3-4-5-6
$$

Submitted School Rankings: The students submit the following school rankings:

\begin{tabular}{l|llll} 
& $\begin{array}{l}\text { 1st } \\
\text { Choice }\end{array}$ & $\begin{array}{l}\text { 2nd } \\
\text { Choice }\end{array}$ & $\begin{array}{l}\text { 3rd } \\
\text { Choice }\end{array}$ & $\begin{array}{l}\text { Last } \\
\text { Choice }\end{array}$ \\
\hline Student 1 & Huron & Clair & Ontario & Erie \\
\hline Student 2 & Huron & Ontario & Clair & Erie \\
\hline Student 3 & Ontario & Clair & Erie & Huron \\
\hline Student 4 & Huron & Clair & Ontario & Erie \\
\hline Student 5 & Ontario & Huron & Clair & Erie \\
\hline Student 6 & Clair & Erie & Ontario & Huron \\
\hline
\end{tabular}

This allocation method consists of the following steps:

Step 1 : A fair lottery determines the following student order: 1-2-3-4-5-6. Student 1 has ranked Huron as his top choice. However, the only slot at Huron is tentatively held by student 5 . So student 5 is moved to the top of the queue.

Step 2 : The modified queue is now 5-1-2-3-4-6. Student 5 has ranked Ontario as his top choice. However, the only slot at Ontario is tentatively held by student 6 . So student 6 is moved to the top of the queue.

Step 3 : The modified queue is now 6-5-1-2-3-4. Student 6 has ranked Clair as her top choice. The two slots at Clair are tentatively held by students 1 and 2 . Between the two, student 1 is ahead in the queue. So student 1 is moved to the top of the queue.

Step 4 : The modified queue is now 1-6-5-2-3-4. Remember that student 1 has ranked Huron as his top choice. A cycle of applications is now made in sequence in 
the last three steps: student 1 applied to the tentative assignment of student 5, student 5 applied to the tentative assignment of student 6 , and student 6 applied to the tentative assignment of student 1 . These mutually beneficial exchanges are carried out: student 1 is assigned a slot at Huron, student 5 is assigned a slot at Ontario, and student 6 is assigned a slot at Clair. These students as well as their assignments are removed from the system.

Step 5 : The modified queue is now 2-3-4. There is one slot left at Clair and two slots left at Erie. Student 2 applies to Clair, which is her top choice between the two schools with remaining slots. Since student 2 tentatively holds a slot at Clair, her tentative assignment is finalized. Student 2 and her assignment are removed from the system.

Step 6 : The modified queue is now 3-4. There are two slots left at Erie. Student 3 applies to Erie, which is the only school with available slots. Since Student 3 tentatively holds a slot at Erie, her tentative assignment is finalized. Student 3 and her assignment are removed from the system.

Step 7 : The only remaining student is student 4 . There is one slot left at Erie. Student 4 applies to Erie for the last available slot. Since Student 4 tentatively holds a slot at Erie, his tentative assignment is finalized. Student 4 and his assignment are removed from the system.

Final assignment Based on this method, the final allocations are:

\begin{tabular}{c|cccccc} 
Student & 1 & 2 & 3 & 4 & 5 & 6 \\
\hline School & Huron & Clair & Erie & Erie & Ontario & Clair
\end{tabular}




\section{Illustration}

\begin{tabular}{|c|c|c|c|c|}
\hline & Queue & Available Slots & $\begin{array}{l}\text { The top student in the queue applies } \\
\text { to a school. }\end{array}$ & At the end of the step \\
\hline Step 1 & $1-2-3-4-5-6$ & $\begin{array}{l}\text { Clair Clair } \\
\text { Erie Erie } \\
\text { Huron Ontario }\end{array}$ & $\begin{array}{l}1 \text { applies to her } 1 \text { st choice Huron, } \\
\text { which is tentatively assigned to } 5 \text {. }\end{array}$ & 5 comes to the top. \\
\hline Step 2 & $5-1-2-3-4-6$ & $\begin{array}{l}\text { Clair Clair } \\
\text { Erie Erie } \\
\text { Huron Ontario }\end{array}$ & $\begin{array}{l}5 \text { applies to her } 1 \text { st choice Ontario } \\
\text { which is tentatively assigned to } 6 .\end{array}$ & 6 comes to the top. \\
\hline Step 3 & $6-5-1-2-3-4$ & $\begin{array}{l}\text { Clair Clair } \\
\text { Erie Erie } \\
\text { Huron Ontario }\end{array}$ & $\begin{array}{l}6 \text { applies to her } 1 \text { st choice Clair, } \\
\text { which is tentatively assigned to } 1 \\
\text { and } 2 \text {. }\end{array}$ & $\begin{array}{l}1 \text { comes to the top. } \\
\text { 6-5-1-2-3-4 }\end{array}$ \\
\hline Step 4 & $1-6-5-2-3-4$ & $\begin{array}{l}\text { Clair Clair } \\
\text { Erie Erie } \\
\text { Huron Ontario }\end{array}$ & A cycle happens in the last 3 steps. & $\begin{array}{l}1 \text { gets a slot at } \underline{\text { Huron. }} \\
5 \text { gets a slot at } \underline{\text { Ontario. }} . \\
6 \text { gets a slot at } \underline{\text { Clair. }}\end{array}$ \\
\hline Step 5 & $2-3-4$ & $\begin{array}{l}\text { Clair } \\
\text { Erie Erie }\end{array}$ & 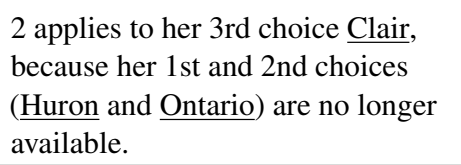 & $\begin{array}{l}2 \text { gets a slot at Clair, } \\
\text { because she is a resident } \\
\text { in Clair. }\end{array}$ \\
\hline Step 6 & $3-4$ & Erie Erie & $\begin{array}{l}3 \text { applies to Erie which is } \\
\text { still available. }\end{array}$ & $\begin{array}{l}3 \text { gets a slot at Erie, } \\
\text { because he is a } \\
\text { resident in Erie. }\end{array}$ \\
\hline Step 7 & 4 & Erie & 4 applies to Erie. & $\begin{array}{l}4 \text { gets a slot at Erie, } \\
\text { because she is a } \\
\text { resident in Erie. }\end{array}$ \\
\hline
\end{tabular}

Final assignment Based on this method, the final allocations are:

\begin{tabular}{c|cccccc} 
Student & 1 & 2 & 3 & 4 & 5 & 6 \\
\hline School & Huron & Clair & Erie & Erie & Ontario & Clair
\end{tabular}




\section{References}

Abdulkadiroğlu, A., Che, Y.-K., \& Yasuda, Y. (2011). Resolving conflicting preferences in school choice: The "Boston mechanism" reconsidered. American Economic Review, 101(1), 399-410.

Abdulkadiroğlu, A., Pathak, P. A., \& Roth, A. E. (2005). The New York City high school match. American Economic Review, 95(2), 364-367.

Abdulkadiroğlu, A., Pathak, P. A., Roth, A. E., \& Sönmez, T. (2005). The Boston public school match. American Economic Review, 95(2), 368-371.

Abdulkadiroğlu, A., Pathak, P. A., Roth, A. E., \& Sönmez, T. (2006). Changing the Boston school choice mechanism: Strategy-proofness as equal access. Harvard University, Working paper.

Abdulkadiroğlu, A., \& Sönmez, T. (2003). School choice: A mechanism design approach. American Economic Review, 93(3), 729-747.

Calsamiglia, C., Haeringer, G., \& Klijn, F. (2010). Constrained school choice: An experimental study. American Economic Review, 100(4), 1860-74.

Chen, Y., \& He, Y. (2016). Information acquisition and provision in school choice. University of Michigan, Working paper.

Chen, Y., \& Kesten, O. (2017). Chinese college admissions and school choice reforms: A theoretical analysis. Journal of Political Economy, forthcoming.

Chen, Y., \& Sönmez, T. (2006). School choice: An experimental study. Journal of Economic Theory, 127, 202-231.

Ding, T., \& Schotter, A. (2015). Learning and mechanism design: An experimental test of school matching mechanisms with intergenerational advice. New York University, Working paper.

Ding, T., \& Schotter, A. (2016). Matching and chatting: An experimental study of the impact of network communication on school-matching mechanisms. Games and Economic Behavior, forthcoming.

Dubins, L. E., \& Freedman, D. A. (1981). Machiavelli and the Gale-Shapley algorithm. American Mathematical Monthly, 88, 485-494.

Ergin, H. I., \& Sönmez, T. (2006). Games of school choice under the Boston mechanism. Journal of Public Economics, 90(1-2), 215-237.

Featherstone, C., \& Niederle, M. (2013). Improving on strategy-proof school choice mechanisms: An experimental investigation. Stanford University, Working paper.

Gale, D., \& Shapley, L. S. (1962). College admissions and the stability of marriage. American Mathematical Monthly, 69, 9-15.

He, Y. (2014). Gaming the Boston school choice mechanism in Beijing. Toulouse School of Economics, Working paper.

Klijn, F., Pais, J., \& Vorsatz, M. (2013). Preference intensities and risk aversion in 
school choice: A laboratory experiment. Experimental Economics, 16(1), 1-22. Mullin, C., \& Reiley, D. (2006). Recombinant estimation for normal-form games, with applications to auctions and bargaining. Games and Economic Behavior, 54(1), 159-182.

Pais, J., \& Pintér, Á. (2008). School choice and information: An experimental study on matching mechanisms. Games and Economic Behavior, 64(1), 303-328.

Pais, J., Pintér, Á., \& Veszteg, R. F. (2011). College admissions and the role of information: An experimental study. International Economic Review, 52, 713737.

Pathak, P. A., \& Sönmez, T. (2008). Leveling the playing field: Sincere and sophisticated players in the Boston mechanism. American Economic Review, 98, $1636-1652$.

Pathak, P. A., \& Sönmez, T. (2013). School admissions reform in Chicago and England: Comparing mechanisms by their vulnerability to manipulation. American Economic Review, 103(1), 80-106.

Roth, A. E. (1982). The economics of matching: Stability and incentives. Mathematics of Operations Research, 7, 617-628.

Roth, A. E. (2002). The economist as engineer: Game theory, experimentation, and computation as tools for design economics. Econometrica, 70, 1341-1378.

Vanacore, A. (2012). Centralized enrollment in recovery school district gets first tryout. The Times-Picayune, April 16. 